\title{
Mechanisms Controlling the Annual Cycle of Precipitation in the Tropical Atlantic Sector in an Atmospheric GCM*
}

\author{
M. Biasutti, D. S. Battisti, And E. S. SARAchiK \\ Department of Atmospheric Sciences, University of Washington, Seattle, Washington
}

(Manuscript received 29 September 2003, in final form 6 May 2004)

\begin{abstract}
A set of AGCM experiments is used to study the annual cycle of precipitation in the region surrounding the tropical Atlantic Ocean. The experiments are designed to reveal the relative importance of insolation over land and the (uncoupled) SST on the annual cycle of precipitation over the tropical Atlantic Ocean, Africa, and the tropical Americas.

SST variations impact the position of the maritime ITCZ by forcing the hydrostatic adjustment of the atmospheric boundary layer and changes in surface pressure and low-level convergence. The condensation heating released in the ITCZ contributes substantially to the surface circulation and the maintenance of the SST-induced ITCZ anomalies.

The remote influence of SST is felt in equatorial coastal areas and the Sahel. The circulation driven by condensation heating in the maritime ITCZ extends to the coastal regions, thus communicating the SST signal onshore. Conversely, the Sahel responds to variations in SST through boundary layer processes that do not involve the maritime ITCZ. The atmospheric response to changes in subtropical SST is advected inland and forces changes in sea level pressure and low-level convergence across a large part of tropical Africa.

The impact of local insolation on continental precipitation can be explained by balancing net energy input at the top of the atmospheric column with the export of energy by the divergent circulation that accompanies convection. Increased insolation reduces the stability of the atmosphere in the main continental convection centers, but not in monsoon regions.

Insolation over land impacts the intensity of the maritime ITCZ via its influence on precipitation in Africa and South America. Reduced land precipitation induces the cooling of the Atlantic upper troposphere and the enhancement of convective available potential energy in the maritime ITCZ.
\end{abstract}

\section{Introduction}

Decomposing the observed annual cycle of precipitation over the tropical Atlantic, South America, and Africa into fundamental building blocks is crucial in itself as a test of our understanding of basic climate processes. Moreover, it can provide powerful tools for diagnosing the reasons behind the shortcomings of current models, and guidance in the investigation of interannual variability. The latter expectation rests on the fact that the Atlantic interannual variability has long been interpreted as a modulation of the annual cycle (e.g., Hastenrath 1984; Mitchell and Wallace 1992) and is strongly affected by the annual cycle of the basic state (Biasutti 2000).

\footnotetext{
* Joint Institute for the Study of the Atmosphere and Oceans Contribution Number 1004.
}

Corresponding author address: Michela Biasutti, Lamont-Doherty Earth Observatory of Columbia University-Oceanography, 61 Route 9W, P.O. Box 1000, Palisades, NY 10968-8000.

E-mail: biasutti@1deo.columbia.edu
This study aims at understanding the processes that govern the annual cycle of precipitation over the Atlantic sector as simulated by a global atmospheric general circulation model (GCM). We identify the processes that directly force the annual cycle of precipitation as a response to local forcing and boundary conditions (insolation and SST) and the processes that couple the continental climate to the climate of the tropical ocean. Specifically, in this paper we discuss how changes in local insolation affect precipitation over the tropical continents, how changes in SST (which in our model experiments can be prescribed independently from insolation) affect precipitation in the ITCZ, and how changes in temperature and rainfall over the ocean affect precipitation over the continents and vice versa.

A companion study (Biasutti et al. 2005, hereafter BBS2) addresses modifications to the mutual influences of land and ocean described here that arise from coupled interactions of the atmosphere and the ocean.

In this study, we focus on the monthly mean, largescale fields, with the understanding that the large-scale features are the backdrop for rain-bearing synoptic and mesoscale processes. Thus, while recognizing the sin- 
TABLE 1. List of experiments: name, insolation forcing, SST boundary conditions, condensational heating over land, condensational heating over the oceanic ITCZ region.

\begin{tabular}{|c|c|c|c|c|c|}
\hline Name & Insolation & SST & $\begin{array}{l}\text { Land } \\
\text { condensational } \\
\text { heating }\end{array}$ & $\begin{array}{c}\text { ITCZ } \\
\text { condensational } \\
\text { heating }\end{array}$ & Relevant figures \\
\hline Control (CTL) & Climatological & Climat. & Calculated (= climat.) & $\begin{array}{l}\text { Calculated } \\
\quad(=\text { climat. })\end{array}$ & Fig. 1 \\
\hline $\begin{array}{l}\text { Varying insolation } \\
\quad(\text { PMS })\end{array}$ & Climatological & Mar & Calculated ( climat.) & $\begin{array}{l}\text { Calculated } \\
\qquad(\sim \text { Mar })\end{array}$ & Figs. 2, 3, 9a, 10a, c, e \\
\hline Varying SST (PVE) & Vernal equinox & Climat. & Calculated ( Mar) & $\begin{array}{l}\text { Calculated } \\
\qquad(\sim \text { Climat. })\end{array}$ & Figs. 4a, 5a, 6, 7, 8 \\
\hline Perpetual Mar & Vernal equinox & Mar & Calculated ( Mar) & $\begin{array}{l}\text { Calculated } \\
\quad(\sim \text { Mar })\end{array}$ & Figs. $4 b, 5 b, 9 b, 10 d, f$ \\
\hline $\begin{array}{l}\text { Perpetual Mar with } \\
\text { Sep ITCZ heating }\end{array}$ & Vernal equinox & Mar & Calculated ( Climat.) & Imposed (=Sep) & Figs. $4 b, 5 b$ \\
\hline $\begin{array}{l}\text { Perpetual Mar with } \\
\text { Jun African and } \\
\text { South American } \\
\text { heating }\end{array}$ & Vernal equinox & Mar & $\begin{array}{l}\text { Imposed over South } \\
\text { America and Africa } \\
\text { (=Jun) }\end{array}$ & $\begin{array}{l}\text { Calculated } \\
\qquad(\sim \text { climat. })\end{array}$ & Figs. 9b, 10b, f \\
\hline $\begin{array}{l}\text { Perpetual Mar with } \\
\text { Jun South African } \\
\text { heating }\end{array}$ & Vernal equinox & Mar & $\begin{array}{l}\text { Imposed over South } \\
\text { Africa (= Jun) }\end{array}$ & $\begin{array}{l}\text { Calculated } \\
\qquad(\sim \text { climat. })\end{array}$ & Fig. 11a \\
\hline $\begin{array}{l}\text { Perpetual Mar with } \\
\text { Jun South Ameri- } \\
\text { can heating }\end{array}$ & Vernal equinox & Mar & $\begin{array}{l}\text { Imposed over South } \\
\text { America (= Jun) }\end{array}$ & $\begin{array}{l}\text { Calculated } \\
\qquad(\sim \text { climat. })\end{array}$ & Fig. $11 b$ \\
\hline
\end{tabular}

gularity of rain events at each location and in each season, we hope to build a conceptual model that can explain the coarse features of the simulated annual cycle in the Atlantic sector and, by extension, in the Tropics.

In its focus on mechanisms, this paper complements our previous work (Biasutti et al. 2003, hereafter BBS1). BBS1 documented where remote influences were most important in producing the simulated annual cycle of surface air temperature and precipitation and also explored issues of nonlinearity in combining the effects of local and remote forcings.

The paper is organized as follows. In the remainder of this section we present our experimental design and a review of the main results of BBS1. We describe the mechanisms responsible for local forcing of continental convection in section 2 , local forcing of oceanic convection in section 3 , oceanic forcing of continental convection in section 4 , and continental forcing of oceanic convection in section 5. Section 6 summarizes the paper.

\section{a. Experimental design}

We employ an atmospheric general circulation model (AGCM) to artificially decompose the annual cycle into "locally generated" and "remotely generated" components by separately imposing SST and insolation as if they were two independent forcings. We allow annual variations in only one of the forcings at a time (either SST or insolation) and prescribe a fixed, arbitrary value for the other one. While SST is obviously not independent of insolation, we can simulate these conditions in our AGCM experiments because SST is prescribed.

The simulations presented in this paper are listed in Table 1, together with a description of the forcings used in each experiment and a reference to the relevant figures.

We present results from two main experiments: the "varying insolation" experiment [the perpetual March SST (PMS) simulation of BBS1] and the "varying SST" experiment [the perpetual vernal equinox (PVE) simulation of BBS1]. The annual cycle in the varying insolation experiment-in which insolation varies annually while SST is fixed at March value-is the response to insolation changes over land. Thus this experiment indicates where the annual cycle over land is driven locally and where the annual cycle over the ocean is forced remotely by circulation changes over the continents, subject to the restriction of fixed SST. The varying SST experiment-in which SST varies annually while insolation is fixed at its 21 March value-indicates where the annual cycle of precipitation over the ocean is driven by the local SST and where the annual cycle over land is remotely forced by SST changes.

Additionally, we present experiments in which both insolation and SST are kept fixed at March values, and the latent heat released in convection in selected tropical areas is prescribed to a value corresponding to different boundary conditions. The prescribed heating is taken from either the varying SST experiment or the varying insolation experiment and corresponds to September SST conditions or June insolation conditions, respectively. (See the discussion in the following sections for a more complete description of these experiments.) We compare these experiments with a control perpetual March simulation (perpetual 21 March insolation and fixed March SST) in order to assess the atmospheric response to elevated condensation heating when everything else is left unchanged. We caution the reader that, 
because the heating is specified, these experiments are not constrained to conserve heat.

We use the (National Center for Atmospheric Research (NCAR) Community Climate Model, version 3 (CCM3) at the standard resolution (19 levels in the vertical and T42 wave truncation, corresponding to a $2.8^{\circ}$ by $2.8^{\circ}$ horizontal grid). All simulations that have an annual cycle in the forcing were run for at least $12 \mathrm{yr}$; the first 4 yr were discarded, and the analysis was conducted on the average of the remaining years. Simulations in which all forcings were kept constant were run for 12 months. All the features discussed in the paper have been verified to be significant at the $95 \%$ level.

It is worth emphasizing that this is a modeling study and that our results are only valid in the framework of an atmospheric GCM with prescribed SST. Moreover, some of our results might be specific to CCM3 and might be influenced by that model's biases and characteristics (Hack et al. 1998; BBS1).

\section{b. The precipitation response to insolation and SST forcings}

Figure 1 summarizes the main results detailed in BBS1. Shown are the first empirical orthogonal function (EOF) and first principal component (PC) of the annual cycle of precipitation in the tropical Atlantic sector in the control simulation, the varying insolation simulation, and the varying SST simulation. The EOF, PC pair in each row of Fig. 1 gives a compact description of the main spatial and temporal characteristics of the annual cycle of precipitation that is forced in the AGCM by the annual cycle of SST and insolation (Figs. 1a,b), insolation only (Figs. 1c,d), and SST only (Figs. 1e,f). For example, Fig. 1a shows that the main characteristic of the control annual cycle is a north-south movement of the major precipitation centers in both the ocean and land.

The similarity of Figs. 1c and 1a over the continents indicates that forcing by the local insolation is sufficient to recreate the annual meridional march of precipitation over the continents. Both Figs. $1 \mathrm{~b}$ and $1 \mathrm{~d}$ indicate that maximum precipitation over the continents occurs during the summer months. Yet, when only the insolation forcing is applied (Fig. 1d), African precipitation reaches the farthest north in June, and not in August, as seen in observations and in the control experiment (Fig. 1b); this phase relationship is also apparent in the raw annual cycle and is not an artifact of EOF analysis. The positive loadings of EOF 1 over the Atlantic ITCZ in Fig. 1c indicate that the insolation-induced annual cycle of continental climate remotely forces an annual cycle in the intensity of the maritime ITCZ; the ITCZ is stronger in conjunction with weaker precipitation in South America and South Africa.

The north-south dipole straddling the mean ITCZ position in Fig. 1e indicates that, in the prescribed SST experiments, SST determines the meridional march of the ITCZ. The ITCZ reaches its northernmost position in September and its southernmost position in March (Fig. 1f), following the highest SST. The same SSTinduced north-south displacement is apparent in the precipitation field over the coastal regions in northeast South America and Africa, and over central Africa, the Sahel, and Sudan.

\section{Local control of continental precipitation}

Neelin and Held (1987) show how, in the thermally direct circulations of the Tropics, a net influx of energy in the atmospheric column $\left(F_{\text {net }}\right.$, the net downward radiative fluxes at the top of the column plus the upward radiative and turbulent fluxes at the surface) is balanced by the export of moist static energy by the divergent circulation. Neelin and Held derive this conclusion from an analysis of the dominant balance in the equations of energy and moisture in the precipitating regions of the Tropics. They develop their argument in terms of the moist static energy; for consistency with the rest of the paper, we will recast it in terms of equivalent potential temperature.

We describe the energy of a moist air parcel as $c_{p} \theta_{e}$, where $c_{p}$ is the atmospheric heat capacity at constant pressure and $\theta_{e}$ is the equivalent potential temperature. The total rate of change in $c_{p} \theta_{e}$ equals the total energy input,

$$
D_{t} c_{p} \theta_{e}=\partial_{t} c_{p} \theta_{e}+\nabla \cdot c_{p} \theta_{e} \mathbf{V}+\partial_{p} c_{p} \theta_{e} \omega=g \partial_{p} F,
$$

where $F$ is the total vertical energy flux, that is, the sum of the radiative, sensible, and latent vertical heat fluxes. If we take the vertical integral over the atmospheric column (indicated with $\langle\cdot\rangle$ ), and the time mean, the first and third term in the lhs vanish and we obtain $\langle\nabla$ $\left.\cdot c_{p} \theta_{e} \mathbf{V}\right\rangle=F_{\text {bottom }}-F_{\text {top }}$.

Neelin and Held now make two major assumptions. First, they assume the vertical structure of convective regions to be the first baroclinic mode (thus, the lowerlevel convergence is equal and opposite to the upperlevel convergence). Second, they assume that horizontal gradients of both temperature and moisture are negligible in the Tropics and so is the transport by transients. Under these approximations, the equation for the vertically integrated mean equivalent potential temperature simplifies to

$$
\left(\theta_{e}^{\text {lowerlevel }}-\theta_{e}^{\text {upperlevel }}\right) \boldsymbol{\nabla} \cdot \mathbf{V}^{\text {lowerlevel }} \propto F^{\text {bottom }}-F^{\text {top }} .
$$

In regions of deep convection, the adiabatic cooling and the diabatic heating nearly balance, so $\Delta \theta_{e}=\theta_{e}^{\text {upper }}-$ $\theta_{e}^{\text {lower }} \approx 0$. However, Neelin and Held note that, for the time-mean circulation to be thermally direct, $\Delta \theta_{e}$ must be positive. Thus, in this simple model, low-level convergence and precipitation require $F_{\text {net }}=F_{\text {bottom }}-F_{\text {top }}$ to be positive. The intuitive interpretation is that a positive import of energy is balanced by the horizontal export by a thermally direct, divergent circulation. Thus, the Neelin and Held model uses a thermodynamic quan- 

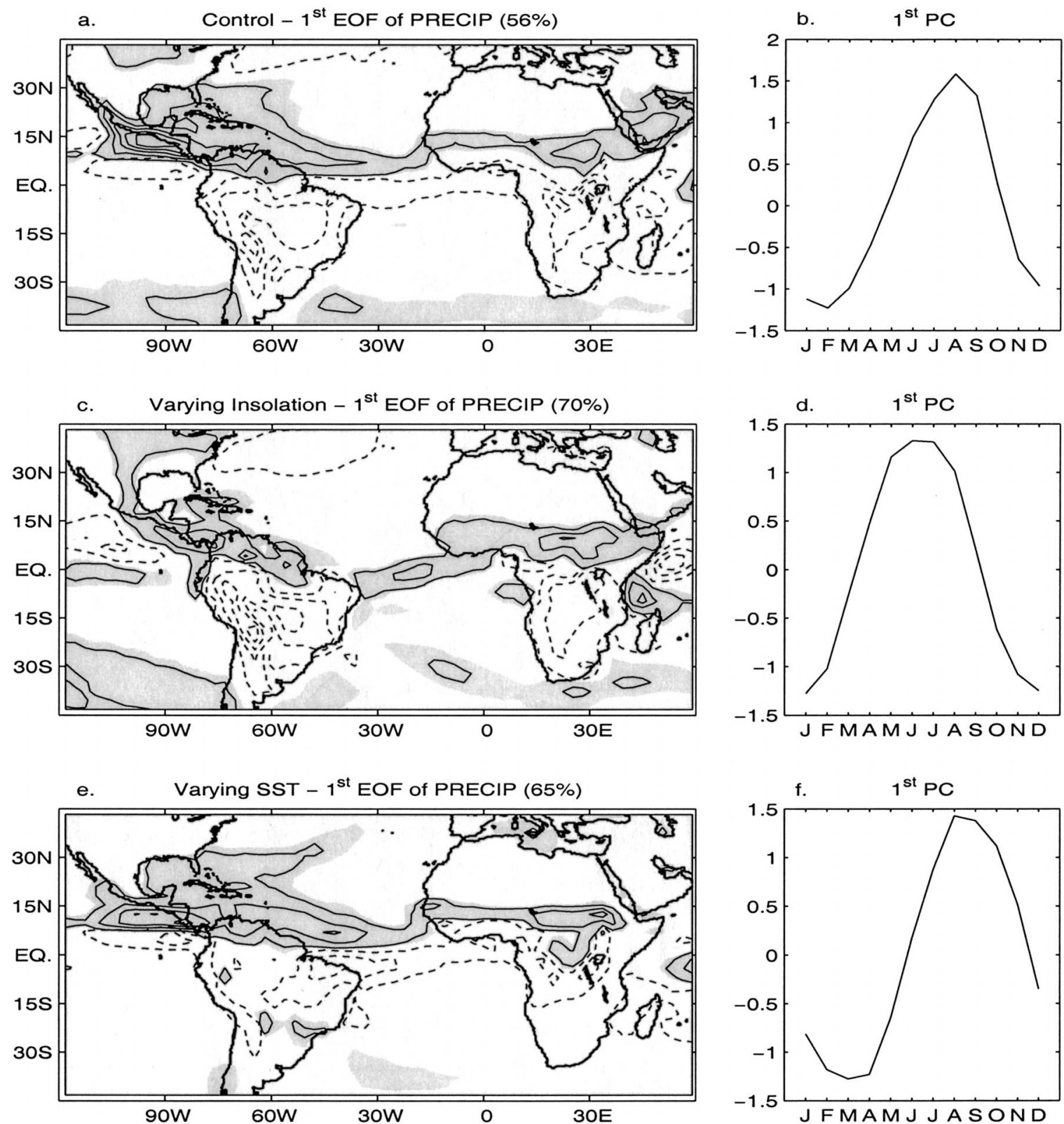

FIG. 1. First EOF and PC of the annual cycle of precipitation in (a),(b) the control run, (c),(d) the experiment with varying insolation and SST fixed at Mar value, and (e),(f) the experiment with varying SST and insolation fixed at Mar value. (a),(c),(e) The contour interval is $2 \mathrm{~mm}$ day $^{-1}$ per standard deviation, starting with \pm 1 . Dashed contours indicate negative values. The shading indicates positive values.

tity to diagnose the occurrence of convection and thermally direct circulations.

There is some circularity in this argument. The model assumes that the atmospheric column can be described by the first baroclinic mode and thus should only be applied to describe an atmospheric column in which convection is occurring, and Sobel et al. (2004) show that indeed cloud radiation feedback can be a determining factor. Similarly, the energy input into a column is determined in part by whether convection is occurring in it. Finally, we remark that while the argument appears to be strictly thermodynamic, the dynamics of the tropical atmosphere are assumed.

Nevertheless, recent studies indicate that $F_{\text {net }}$ can be used as a zeroth-order indicator of where convection is possible. For example, Sobel and Bretherton (2000) show that a model based on the balance of $F_{\text {net }}$ and the divergent circulation captures the distribution of convective regions in the Tropics equatorward of $15^{\circ}$, although they also show that the addition of moisture advection improves the simulation. Chou and Neelin (2003) show an overall good correspondence between 


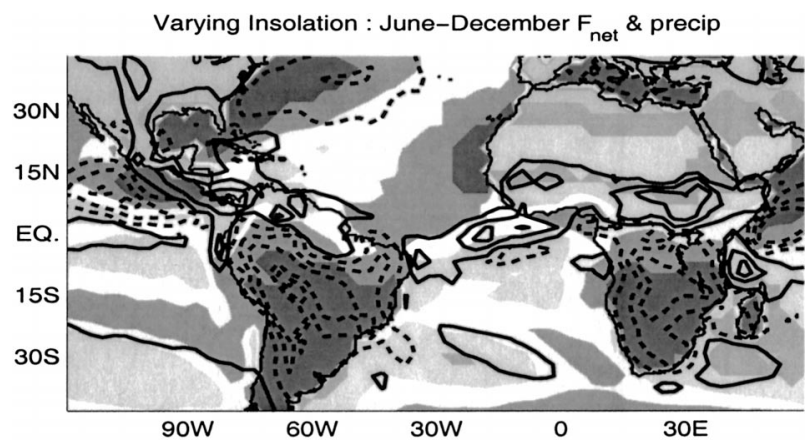

FIG. 2. Varying insolation experiment. Jun-Dec precipitation (contoured, c.i. $=4 \mathrm{~mm} \mathrm{day}^{-1}$, starting with \pm 2 , negative values dashed) and total energy flux into the atmosphere $F_{\text {net }}$ (shaded, interval of 50 $\mathrm{W} \mathrm{m} \mathrm{m}^{-2}$ starting at $\pm 25 \mathrm{~W} \mathrm{~m}^{-2}$, dark gray shading indicates negative values less than $-25 \mathrm{~W} \mathrm{~m}^{-2}$, white indicates value between \pm 25

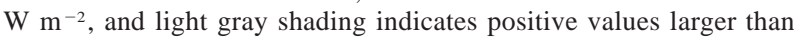
$25 \mathrm{~W} \mathrm{~m}^{-2}$ ).

regions of positive $F_{\text {net }}$ and precipitation during July both in observations and in an intermediate complexity model. Our GCM simulations also reproduce the hypothesized coincidence of rainfall and positive $F_{\text {net }}$ over most of the tropical land, but not in the Atlantic ITCZ or in land regions affected by the ITCZ (e.g., the Guinea coast).

Over land, where the negligible heat capacity of the soil makes the energy flux into the surface vanish on time scales longer than a day, the requirement of a positive $F_{\text {net }}$ for the development of convection translates into the requirement of a downward energy flux at the top of the atmosphere. Therefore, it is tempting to explain the influence of insolation on the annual cycle of precipitation in the tropical continents in terms of $F_{\text {net }}$. Figure 2 shows the seasonal change (June-December) in precipitation brought about by insolation only, superimposed on the corresponding change in total column energy flux $\left(F_{\text {net }}\right)$. It is apparent that, to zeroth order, changes in $F_{\text {net }}$ and changes in precipitation over land go together: where the June-December $F_{\text {net }}$ is negative, so is the precipitation change and vice versa. A notable exception is the Sahara, where dryness and high albedo make $F_{\text {net }}$ negative all year-around in our simulations (not shown) as well as-to a lesser extent-in observations (Chou and Neelin 2003).

The idealized model outlined above has the merit of framing the question of where convection can occur in terms of the energetics of the atmosphere, but says nothing about the processes at play. In order to gain some insight as to how the added energy that comes from summer insolation translates into added convection, we need to look at the vertical structure of the atmosphere in more detail. Although deep convection over the continents is strongly modulated by the diurnal cycle and varies on short temporal and spatial scales, the monthly mean, area-mean vertical profiles of potential temperature $(\theta)$, equivalent potential temperature $\left(\theta_{e}\right)$, and saturated equivalent potential temperature $\left(\theta_{\mathrm{es}}\right)$ are good indicators of where deep convection can be sustained by the large-scale environment. Convection occurs when the free troposphere is unstable or neutral to moist convection $\left(\partial_{z} \theta_{\mathrm{es}} \leq 0\right)$ and when a mixed-layer plume can reach the level of free convection $\left[\theta_{\mathrm{es}}=\right.$ $\theta_{e}$ (mixedlayer) at the level of free convection]. Moreover, the seasonal changes in $\theta$ and $\theta_{e}$ indicate whether changes in temperature or in moisture are responsible for changes in convection.

Figure 3 shows how the vertical structure of the atmosphere over two convective regions in Africa is influenced by insolation; it shows the vertical profiles of $\theta, \theta_{e}$, and $\theta_{\mathrm{es}}$ in northern Africa $\left(20^{\circ}-40^{\circ} \mathrm{E}, 6^{\circ}-12^{\circ} \mathrm{N}\right)$ and southern Africa $\left(15^{\circ}-35^{\circ} \mathrm{E}, 5^{\circ}-20^{\circ} \mathrm{S}\right)$. It is apparent that insolation influences the stability of different land regions in different ways. In South Africa, insolation induces a substantial change in the stability of the atmosphere. The low-level austral summer warming is responsible for the erosion of the wintertime inversion at $700 \mathrm{mb}$. This change in stability is responsible, together with the increase in low-level humidity, for making the December "sounding" conditionally unstable (the interception between the $\theta_{\mathrm{es}}$ line and the gray line in Fig. 3d indicates that the level of free convection for surface plumes is at about $750 \mathrm{mb}$ ), supporting the December increase in precipitation in southern Africa.

Conversely, the sounding in northern Africa indicates that the surface temperature and atmospheric stability barely change in response to insolation changes between December and June. What makes the North Africa sounding conditionally unstable is the increased lowlevel moisture due to the monsoon flow (see the insolation-induced changes in $\theta_{e}$ in Fig. 3e). Hence, the role of large-scale circulation is paramount for northern subSaharan Africa, while it is somewhat secondary in the Congo basin, farther to the south. As an aside, we note that, although the raison d'être for the monsoon is the warm continent/cold ocean summer contrast, the monsoon rain falls on land that is no warmer during the summer than it is in winter. It is a truism, but worth repeating: insolation drives the African monsoon by warming up the Sahara, not the regions where the rain ends up falling. We will return to the role of the Sahara in the dynamics of monsoon circulation in section 4 .

\section{Local control of oceanic precipitation}

Figure $4 \mathrm{a}$ shows the difference between September and March precipitation in the varying SST simulation, that is, the response of precipitation to September minus March SST difference. In this section, we will focus on the oceanic portion of the response. In our experiments (which, the reader is reminded, are uncoupled), SST determines the position of the ITCZ: when the belt of highest SST migrates to the north, so does the ITCZ. Note that while this simulation is driven by seasonal changes in SST in the global ocean, the position of the ITCZ changes in response to the local SST (this was 


\section{Varying Insolation}

North Africa

a.

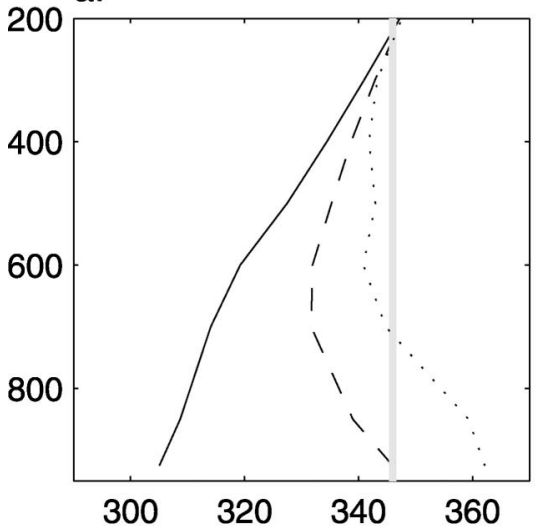

c. December

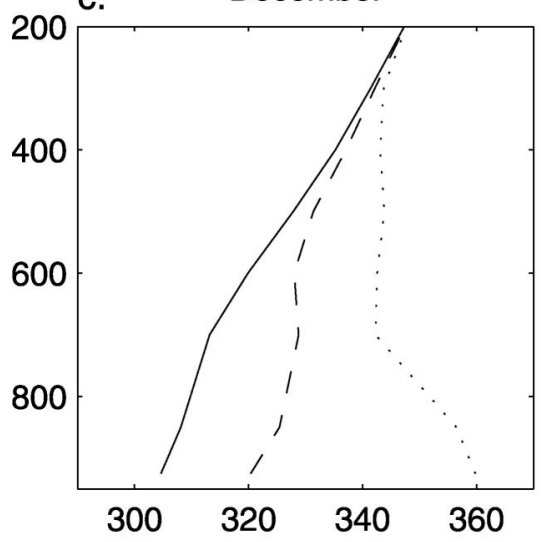

e. June-December

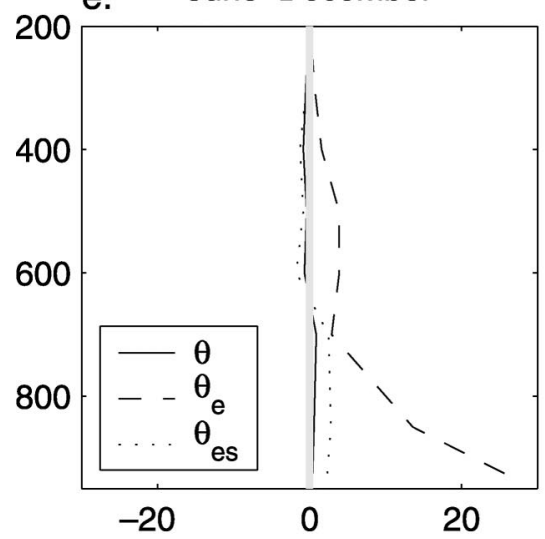

South Africa

b.

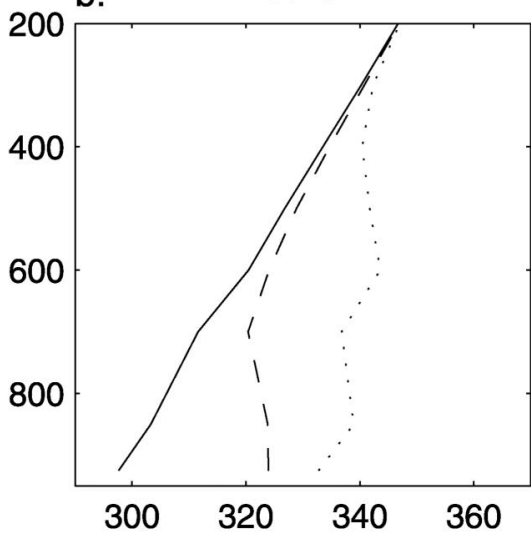

d. December
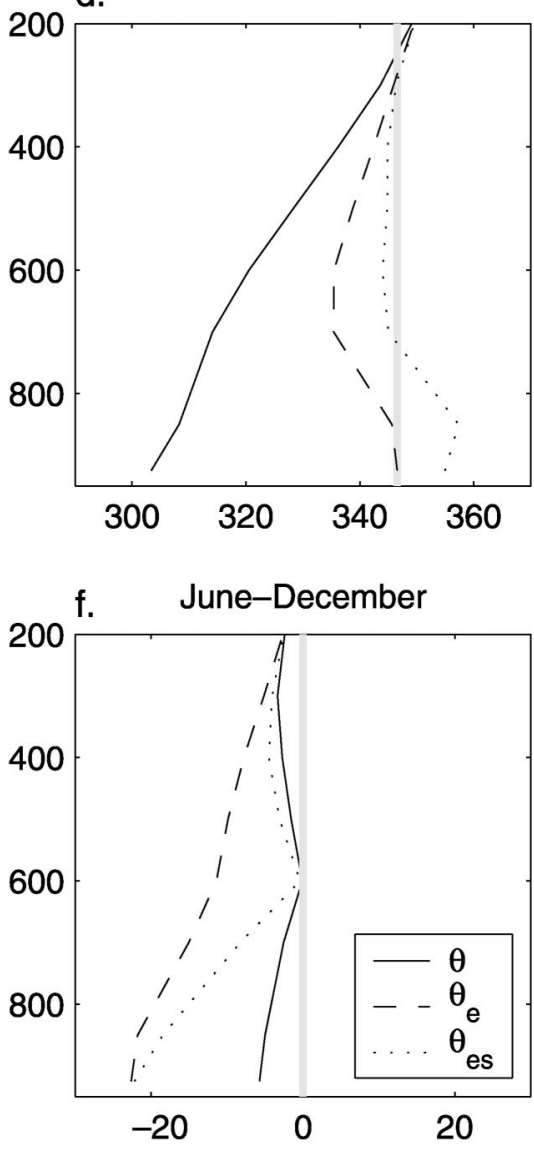

FIG. 3. Vertical profiles of potential temperature $\left(\theta\right.$, solid), equivalent potential temperature $\left(\theta_{e}\right.$, dashed), and saturated equivalent potential temperature ( $\theta_{\mathrm{es}}$, dotted) over (left column) northern Africa $\left(6^{\circ}-12^{\circ} \mathrm{N}\right)$ and (right column) southern Africa $\left(5^{\circ}-20^{\circ} \mathrm{S}\right)$ during (top) Jun and (middle) Dec, and (bottom) the Jun-Dec difference in the varying insolation experiment. (a),(d) The gray vertical lines denote the surface $\theta_{e}$. 

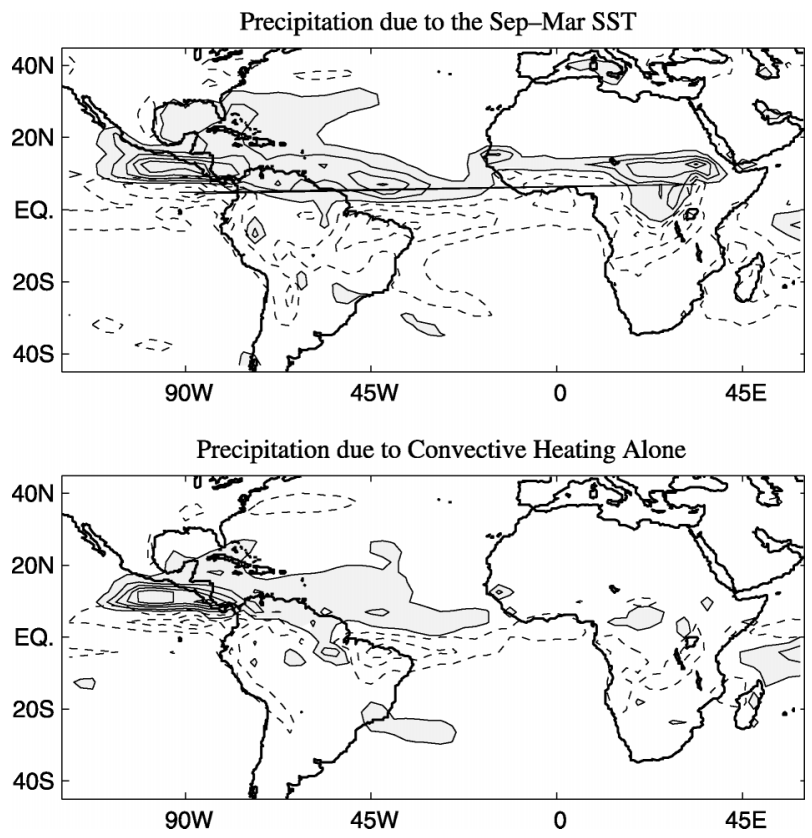

FIG. 4. (top) Sep-Mar precipitation in the varying SST experiment. (bottom) Precipitation anomalies due to Sep-Mar elevated latent heating anomalies in the oceanic ITCZ (perpetual Mar with Sep ITCZ heating-perpetual Mar). The contour interval is $4 \mathrm{~mm}_{\text {day }}{ }^{-1}$, starting with \pm 2 , negative values are dashed, positive values larger than 2 $\mathrm{mm}$ day $^{-1}$ are shaded.

confirmed by an experiment in which SST was changed independently in the Atlantic and in the Indo-Pacific, not shown). This result supports the view of the SSTITCZ coupling first suggested by Lindzen and Nigam (1987) in an uncoupled study of the eddy component of the tropical circulation. The skeleton of the Lindzen and Nigam mechanism is the following: a positive surface temperature perturbation is communicated by turbulent mixing throughout the boundary layer, creates a negative low-level pressure anomaly, and thus influences the boundary layer convergence that sustains convection. Hastenrath and Greischar (1993) have used the same argument to explain the coherent decadal variability in SST and rainfall in the tropical Atlantic. (But note that, when the SST is allowed to vary, the ITCZ can feedback on the ocean; e.g., Chang et al. 1997).

While it is true that boundary layer processes drive the seasonal shift of the ITCZ in an uncoupled setting, convective heating in the ITCZ has itself the potential to thermally drive changes in surface pressure and thus surface wind. The role of elevated condensation heating in driving surface wind was investigated by the theoretical study of Wu et al. (2000a,b) and was quantified for the Pacific in a linearized GCM by DeWitt et al. (1996) and for the Atlantic in an intermediate-complexity model by Chiang et al. (2001). Recently, McGauley et al. (2004) have estimated from observations a minor but sizable influence of elevated conden- sation heating on the sea level pressure and surface winds in the Pacific ITCZ region.

To identify the role of elevated heating in forcing lowlevel winds and convergence, we will refer to a prescribed-heating experiment. This is another AGCM experiment in which both insolation and SST are fixed at March values (perpetual March) and in which the threedimensional heating field was artificially changed. At every time step of the simulation, we discarded the simulated latent heating due to convection in the oceans between $15^{\circ} \mathrm{S}$ and $25^{\circ} \mathrm{N}$ (i.e., we discard the heating associated with the ITCZ for March conditions) and replaced it with a prescribed value taken from the climatology of the varying SST simulation and corresponding to September SST (i.e., we substitute the heating associated with the ITCZ for September conditions). Over land and outside the band between $20^{\circ} \mathrm{S}$ and $30^{\circ} \mathrm{N}$ the model remains free to determine the latent heating released in convection. The transition between the regions forced by prescribed and calculated latent heating is smoothed over two grid points in every direction. We will refer to this simulation as the perpetual March with September ITCZ heating experiment.

Note that the model is free to determine its own precipitation everywhere. Thus, the simulated precipitation and the imposed latent heating are not necessarily consistent. Also, not all the heating associated with convection is prescribed: for example, radiative heating is left for the model to calculate. We wish to disclose that our main reason for constructing this experiment was to look at the remote response to elevated heating in the ITCZ (see section 4). Because of the inherent inconsistency between the heating field and the precipitation, temperature, and stability fields, strong caution is advised in interpreting the local response to an imposed heat source. We will return to this point at the end of this section.

Figure $5 \mathrm{~b}$ shows the difference in surface winds and the column-integrated moisture convergence between the perpetual March with September ITCZ heating experiment and a control perpetual March experiment. (The total moisture convergence is calculated as precipitation minus evaporation, as the change in the storage term is small.) This difference is the response forced by differences in the elevated heating between the September and the March ITCZ. Figure 5a shows the September-March difference in wind and moisture convergence in the varying SST run, and portrays the response to differences in SST. Because the anomalies in Fig. 5b develop in the absence of SST forcing, comparing Figs. 5a and 5b gives a rough estimate of the influence of the elevated condensation heating upon the low-level convergence. We interpret Fig. 5 as follows. In regions where Figs. 5a and $5 \mathrm{~b}$ are substantially different, boundary layer forcing primarily determines the low-level convergence and precipitation, while elevated heating (i.e., precipitation) can be thought of as a passive response. In regions where Figs. 5a and 5b are similar, 

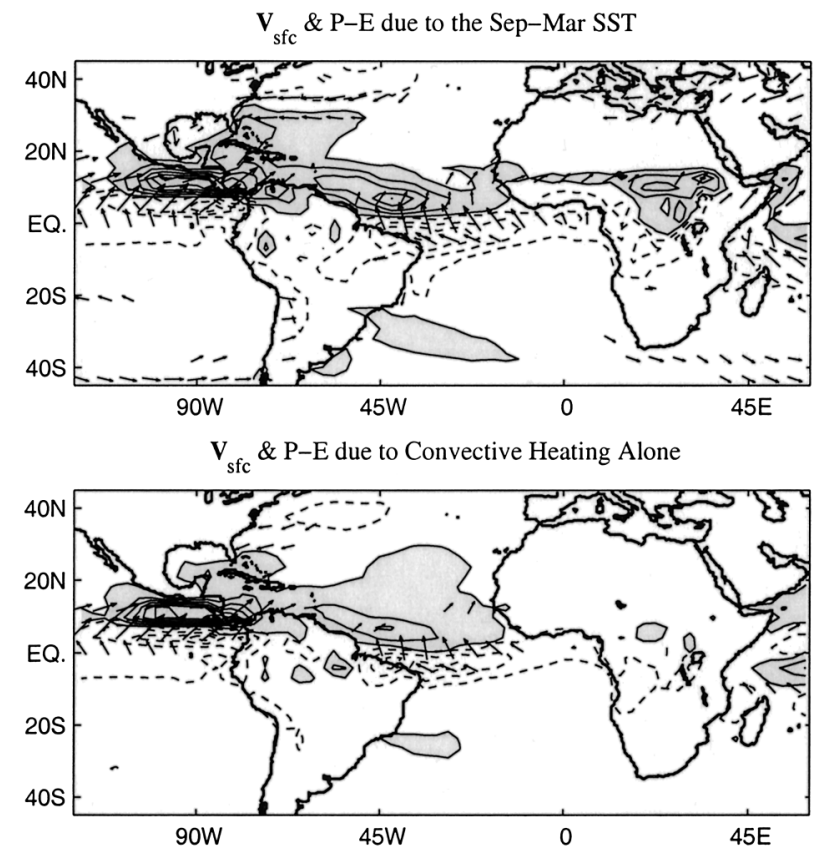

FIG. 5. (top) Sep-Mar surface wind and column-integrated moisture convergence in the varying SST experiment, calculated as precipitation minus evaporation $(\mathrm{P}-\mathrm{E})$. (bottom) Surface wind and columnintegrated moisture convergence $(\mathrm{P}-\mathrm{E})$ anomalies due to Sep-Mar elevated latent heating anomalies in the oceanic ITCZ (perpetual Mar with Sep ITCZ heating-perpetual Mar). The contour interval is 4 mm day ${ }^{-1}$, starting with \pm 2 , negative values are dashed, positive values larger than $2 \mathrm{~mm}_{\text {day }}^{-1}$ are shaded. Only wind vectors larger than $2 \mathrm{~m} \mathrm{~s}^{-1}$ are plotted.

the circulation forced by the elevated condensation heating contributes substantially to the maintenance of the surface winds and low-level convergence initiated by SST. The similarity between Figs. 5a and 5b would suggest that the elevated heating plays a substantial role, in particular in the equatorial western Atlantic and eastern tropical Pacific.

Again, we stress that any quantitative conclusion on the forcing of convergence by the elevated heating is precluded in this experimental design, because of the effect of the imposed heating on stability. The precipitation response to the September-March difference in elevated heating in the tropical Atlantic (Fig. 4b) is weaker than the response to SST (Fig. 4a). However, one cannot measure the intensity of the response to heating on the basis of how much weaker the response is: a weaker response can be easily explained in terms of the effect of the imposed heating on the stability of the atmospheric column. The imposed heating warms the upper troposphere more than the lower troposphere, thus increasing the stability of the atmospheric column or, equivalently, decreasing the convective available potential energy (not shown). Hence, in the region of imposed heating, deep convection is less efficient than in the original simulation (the simulation from which the heating field itself was taken) and precipitation is weaker (cf. Figs. 4a and 4b). The heating anomalies are too strong to be consistent with the precipitation anomalies they force. It follows that imposing the convective heating as an external forcing is problematic if one is interested in the local response. We suggest that only the qualitative aspects of the local response to the heating can be considered robust. The remote response to the elevated heating in the ITCZ is described in the next section.

\section{Oceanic control of continental precipitation}

We have shown in Fig. 1e that annual changes in SST have the ability to force annual changes in precipitation over the continents, specifically in those coastal regions of South America and Africa that border the ITCZ, and in a zonal band that spans the whole of Africa at the latitude of the Sahel. Figure 1f shows that the SST seasonal cycle is responsible for the fact that the African monsoon reaches its northernmost position in late (as opposed to early) summer.

There are two possible ways for SST to influence continental climate: by directly changing the boundary layer wind and the temperature and moisture advected onshore, or by causing anomalies in oceanic precipitation (and thus elevated heating) which, in turn, drive far-reaching circulation anomalies. To elucidate the relative importance of the boundary layer forcing and of the elevated heating forcing in inducing precipitation changes over land, we refer again to the perpetual March with September ITCZ heating experiment introduced in the previous section and presented in Figs. $4 \mathrm{~b}$ and $5 \mathrm{~b}$. We recall that, in this experiment, SST and insolation are kept fixed at March values, while the elevated heating field in the tropical oceans is taken from the varying SST experiment and corresponds to September SST conditions. Because we are now focusing on the remote response, the effect of the imposed heating on local stability is inconsequential and the precipitation difference between the imposed-heating simulation and a control perpetual March simulation (Fig. 4b) is, over land, directly comparable to the September-March precipitation difference in the varying SST experiment (Fig. 4a).

In the Guiana Highlands and Northeast Brazil, the response forced by the ITCZ heating (Fig. 4b) and that forced by SST (Fig. 4a) are very similar, indicating that the influence of the ocean in this region can be explained mainly in terms of the circulation changes that accompany the movement of the ITCZ, in particular the changes in low-level convergence. ${ }^{1}$ This is consistent with the

\footnotetext{
${ }^{1}$ Note that the perpetual March with September ITCZ heating experiment underestimates the anomalies in Colombia and Venezuela, but we attribute this to the fact that the forcing in the eastern Pacific and the Gulf of Mexico is not applied at full strength, because in those regions the forcing is a linear interpolation between the full forcing (over the open ocean) and zero forcing (over the Central American continent and the Caribbean Islands).
} 

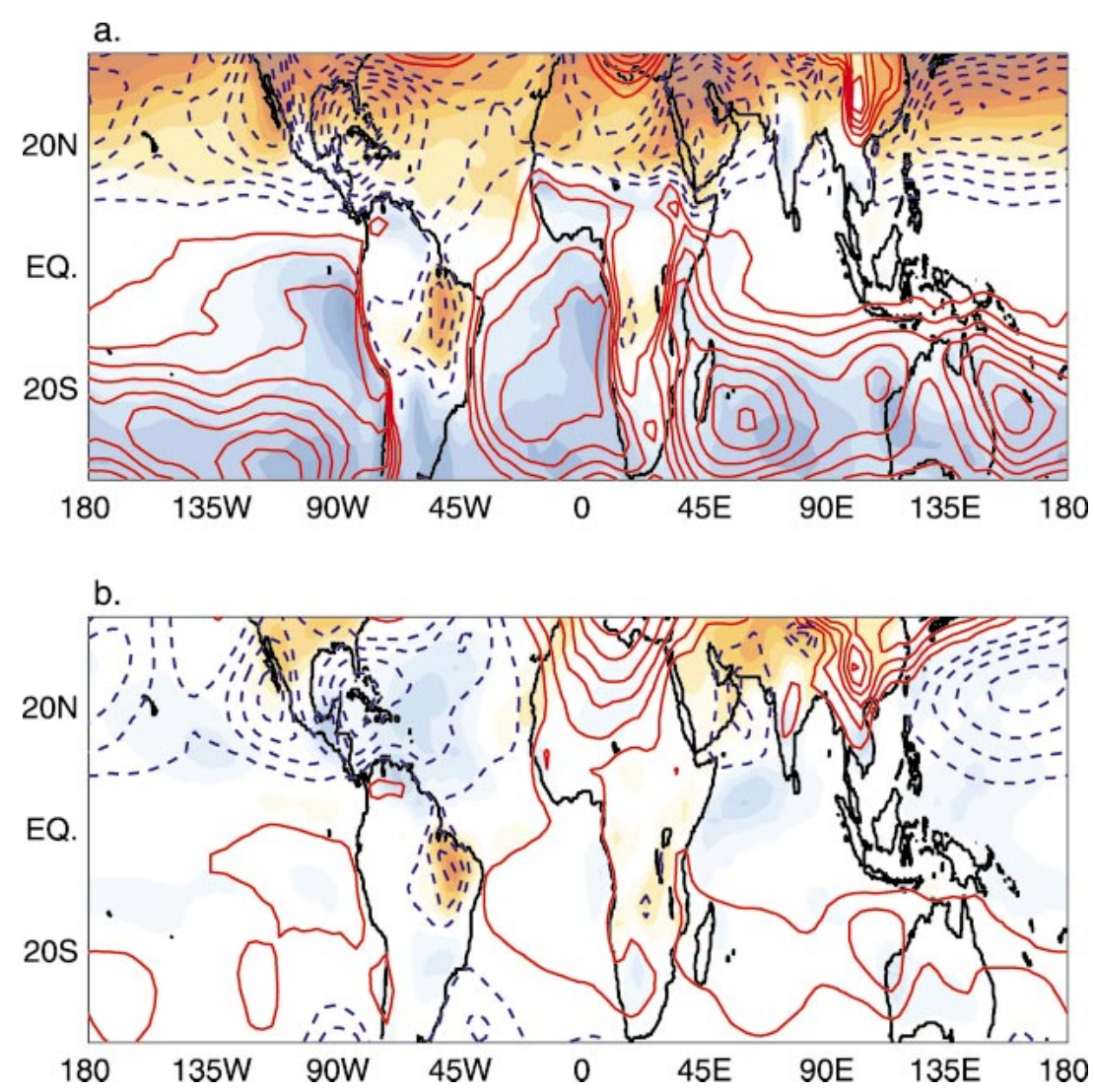

FIG. 6. (top) Sep-Mar SLP and SAT differences in the varying SST experiment. (bottom) SLP and SAT differences due to Sep-Mar elevated latent heating anomalies in the oceanic ITCZ (perpetual Mar with Sep ITCZ heating-perpetual Mar). SLP is contoured (c.i. $=1 \mathrm{mb}$ ), and SAT is shaded $\left(\right.$ c.i. $\left.=1^{\circ} \mathrm{C}\right)$.

fact that most of the SST-induced precipitation changes in coastal South America can be forced by changes in the Atlantic SST alone. Conversely, over Africa the precipitation response to SST is not reproduced by the perpetual March with September ITCZ heating experiment. The ITCZ heating forces anomalies of the right sign in equatorial central Africa, but their magnitude is far too weak. More importantly, the ITCZ heating does not force any coherent anomaly over the Sahel. We conclude that Sahel rainfall is mainly influenced by SST via boundary layer processes and not by the circulation forced by the ITCZ. The ocean influences the Sahel through the advection of maritime boundary layer temperature anomalies over northern Africa; the temperature anomalies, in turn, cause the development of anomalies in sea level pressure (SLP) and in surface wind convergence. Specifically, the SST changes from March to September generate a cross-isobaric southerly wind that converges in the Sahel region, where it generates the observed enhancement in precipitation.

Figure 6a shows the SLP and surface air temperature (SAT) changes generated by the September-March SST difference. The similarity between the changes in SLP and SAT in North Africa supports the interpretation that the SLP changes are a boundary layer response to the SAT anomalies. Figure $6 \mathrm{~b}$ shows the SLP and SAT response to changes in the elevated heating field over the tropical oceans. In response to elevated heating, there are substantial SLP anomalies over the Sahara, but very weak SAT anomalies. More importantly, the low-level wind associated with this pattern of SLP anomalies is not converging in the Sahel (Fig. 5b).

A good indicator of the location of precipitation is the mean boundary layer equivalent potential temperature $\left(\theta_{e}\right)$, which contains information about both temperature and humidity near the earth's surface: the maximum precipitation is collocated with the maximum of $\theta_{e}$. Figure 7 portrays the effect of SST changes on boundary layer $\theta_{e}$, SLP, and precipitation over Africa. The solid (dashed) lines in Figs. a,b portray $\theta_{e}$ (SLP) averaged over $15^{\circ} \mathrm{W}-15^{\circ} \mathrm{E}$ (Fig. 7a, West Africa and the eastern Atlantic) and $15^{\circ}-45^{\circ} \mathrm{E}$ (Fig. $7 \mathrm{~b}$, central Africa) as a function of latitude for September and March SST conditions (in the varying SST simulation). The hatched vertical bands indicate regions of precipitation greater than $5 \mathrm{~mm}$ day $^{-1}$. The correspondence between the precipitation and $\theta_{e}$ maxima is apparent.

During September, the maxima of $\theta_{e}$ and precipitation 

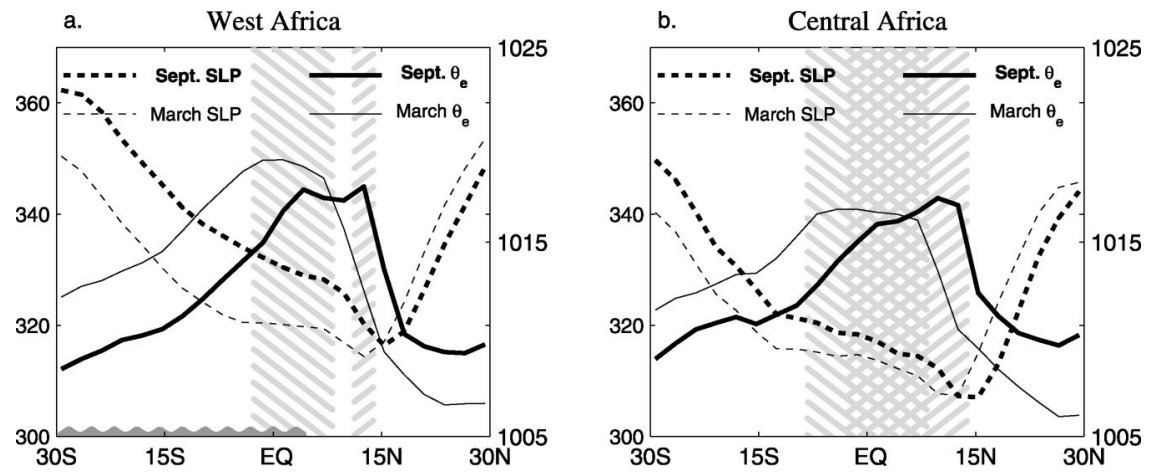

FIG. 7. Sep (thick lines) and Mar (thin lines) latitudinal profiles of boundary layer equivalent potential temperature $\left(\theta_{e}\right.$, solid) and SLP (dashed) over (a) West Africa $\left(15^{\circ} \mathrm{W}-15^{\circ} \mathrm{E}\right)$, and (b) East Africa $\left(15^{\circ}-45^{\circ} \mathrm{E}\right)$ in the varying SST experiment. The hatched gray vertical bands indicate latitudinal bands of precipitation larger than $5 \mathrm{~mm}$ day $^{-1}$ in Sep (positive slope) and in Mar (negative slope). (a) The wavy line at the bottom indicates the extent of the oceanic region.

are shifted to the north, in both West and central Africa. To the south of West Africa, the September-March difference in $\theta_{e}$ is a direct expression of the changes in SST; in the Sahara, the September increase in $\theta_{e}$ is due to changes of land surface temperature, and in the Sahel region it is due to changes in humidity. Similarly, seasonal changes in $\theta_{e}$ in central Africa are due to temperature except in the Sahel, where they are due to humidity. The profiles of $\theta_{e}$ show the important role of changes in the Sahara in shifting the maximum $\theta_{e}$ and precipitation in both western and central Africa.

An additional experiment (not shown), in which we disabled changes in the elevated condensation heating over land, confirms that boundary layer processes alone are sufficient for establishing the bulk of the $\theta_{e}$ response in the Sahel that is due to SST changes. At the same time, it suggests that the feedback provided by the elevated condensation heating is in part responsible for the local humidity changes and the northward shift of precipitation (the shift is reduced by one grid point when the feedback is disabled).

To summarize, the northward shift of precipitation in the Sahel is a consequence of warm SAT anomalies developing in the Sahara in response to the March-toSeptember changes in SST. But, how is the seasonal change of SST communicated inland across the entire African continent? The differences in the temperature advection and subsidence between March and September in the varying SST simulation (not shown) indicate that the anomalies are maintained in equilibrium by horizontal advection. The advection of 1) mean temperature by the anomalous wind, 2) anomalous temperature by the mean wind, and 3) anomalous temperature by the anomalous wind are all of comparable magnitude. What maintains the equilibrium anomalies is not necessarily what created the anomalies in the first place, but we speculate that advection is indeed responsible for communicating the warm SAT anomalies forced over the ocean in the subtropical North Atlantic in the zonal direction, and thus for forcing the bulk of the SAT response in the Sahara.

Many previous studies (Folland et al. 1986; Schneider et al. 2003; Giannini et al. 2003) have linked African rainfall interannual and interdecadal variations to SST forcing from the global ocean. What ocean regions have the strongest influence on the annual cycle of North African rainfall? Figure 8 shows the response of $\theta_{e}$ in West and central Africa to September-March changes in SST that are imposed in all ocean basins, only in the Atlantic, and only in the Indo-Pacific. The bold gray line is the $\theta_{e}$ difference between September and March in the varying SST-only experiments (i.e., the difference between the $\theta_{e}$ profiles in Fig. 7). The remaining lines are difference plots between simulations with varying SST and with fixed SST in one or more ocean basins and provide an alternative estimate of the response to global SST, as well as estimates of the response to SST in each basin. ${ }^{2}$ This figure suggests that western Africa responds predominantly to forcing from the Atlantic SST, while central Africa responds to forcing from all basins. Note that the two estimates of the $\theta_{e}$ response to the global SST derived from the Varying SST-only simulation and from the CTL-PMS difference, respectively, are qualitatively similar, but quantitatively different. This is consistent with the conclusions of BBS1, who noted that insolation and SST interact nonlinearly in the Sahel-Sudan region.

Finally, we note that over the Sahel, the pattern of the precipitation anomalies induced by the SeptemberMarch SST changes (Fig. 4a) is remarkably uniform in

\footnotetext{
${ }^{2}$ Specifically, the estimate of the response to September-March SST anomalies in all basins is given as the difference between a control simulation and one with perpetual March SST (CTL-PMS in BBS1), the response to Atlantic SST-only is given as the difference between CTL and a Perpetual March Atlantic SST experiment (PMAS in BBS1) and the response to the Indo-Pacific SST is given as the PMAS-PMS difference.
} 

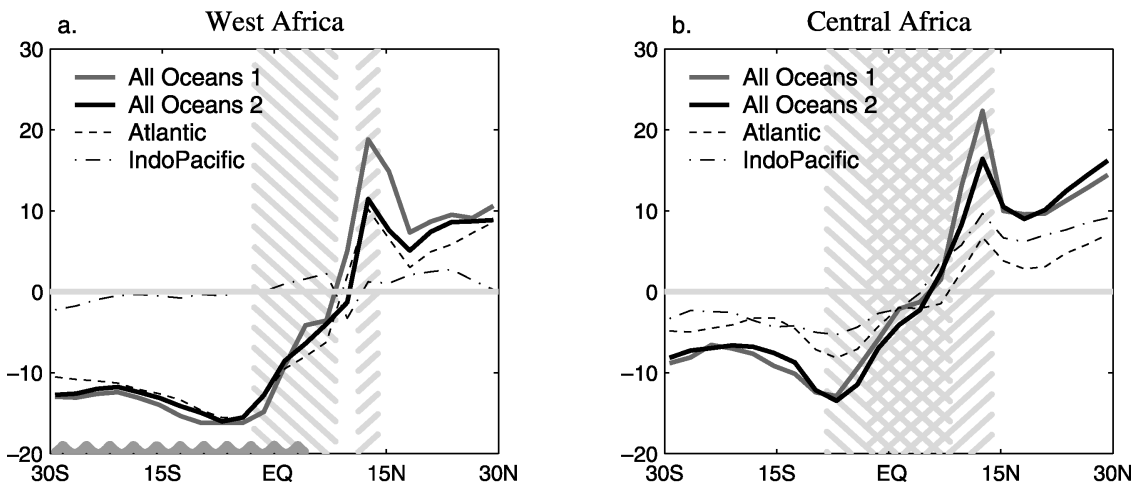

FIG. 8. Latitudinal profiles of differences in boundary layer equivalent potential temperature over (a) West Africa $\left(15^{\circ} \mathrm{W}-15^{\circ} \mathrm{E}\right.$, and (b) East Africa $\left(15^{\circ}-45^{\circ} \mathrm{E}\right)$ due to the Sep-Mar differences in SST over the global ocean (bold gray and black lines), over the Atlantic only (dashed line) and the Indo-Pacific only (dot-dashed line). The two estimates of the response to global SST are the Sep-Mar difference in the varying SST only run (gray line) and the CTL-PMS difference in Sep (black line). The hatched gray vertical bands indicate latitudinal bands of precipitation larger than $5 \mathrm{~mm}$ day $^{-1}$ in Sep (positive slope) and in Mar (negative slope). (a) The wavy line at the bottom indicates the extent of the oceanic region.

the zonal direction. Yet, there are some interesting differences in how SST affects West and central Africa. In central Africa, the SST forcing leaves the latitudinal extent of the precipitation maximum unchanged and the area of maximum precipitation straddles the equator whether SST assumes March or September values (Fig. $7 b)$. The anomalous circulation is mostly limited to the latitude of the Sahel (Fig. 5b). In West Africa, September SST conditions both shift the location of the precipitation maximum and reduce its extent to a narrow band at about $15^{\circ}$ (Fig. 7a). In this region, the anomalous circulation is a cross-equatorial, monsoonlike circulation (Fig. 5b).

\section{Continental control of oceanic precipitation}

Figure 9a shows the June-minus-March difference in the varying insolation simulation, that is, the precipitation changes forced by the June-March changes in insolation over land (Note the similarity between Figs. 9a and 1c). Recall that, in this experiment, SST conditions are fixed at the March value and the position of the ITCZ is anchored by the SST gradient to be near the equator throughout the year. The remote effect of June-March insolation changes over land is to increase the precipitation intensity in the region of the ITCZ by about $6 \mathrm{~mm} \mathrm{day}{ }^{-1}$, with peak anomalies of $10 \mathrm{~mm}$ day $^{-1}$. The location of the ITCZ-when SSTs are prescribed - is not affected by changes over land. (BBS2 shows that this is not the case when the atmosphere is coupled to an ocean.)

How is the increase of oceanic precipitation intensity achieved? There are two main possibilities. The first is that the insolation-induced changes in land surface temperature directly affect the sea level pressure field in such a way as to enhance the intensity of the low-level convergence into the ITCZ. The second possibility is that changes in land temperature force changes in land convection, which in turn induce anomalies in the stability of the atmosphere over the ocean.

Figure 10 (left column) documents the remote effect of insolation-induced seasonal changes over land on the vertical structure of the atmosphere in the ITCZ region; it shows the vertical profiles of $\theta, \theta_{e}$, and $\theta_{\mathrm{es}}$ averaged over the equatorial Atlantic for the months of June and March in the varying insolation simulation. Under June and March insolation conditions alike (Figs. 10a and 10c), the atmosphere is conditionally unstable and the level of free convection (indicated in Fig. 10 by the intersection of $\theta_{\mathrm{es}}$ with the light gray line) is reached just below $900 \mathrm{mb}$. Figure 10e suggests that the heavier precipitation under June insolation condition over land follows a cooling of the upper troposphere over the Atlantic, which is, most likely, due to the reduced convection over the tropical continents. ${ }^{3}$

We hypothesize that June-March land surface temperature changes do not have a direct effect on oceanic precipitation; instead they cause a reduction in deep convection over Africa and South America, which cools the tropical free troposphere and makes the equatorial Atlantic more convective. This mechanism is akin to that explored by Chiang and Sobel (2002) for the Atlantic response to ENSO.

To test this hypothesis, we have performed some additional experiments with a perpetual March configuration of insolation and SST, and a modified elevated

\footnotetext{
${ }^{3}$ Note that Fig. 10e does not indicate an increase in low-level moisture, but that would not necessarily be expected: because the basic state is convective to begin with, any increase in moisture through low-level convergence would likely show up in stronger updrafts and precipitation, and a moistening of the free troposphere, rather than a moistening of the surface. Surface convergence is indeed larger when precipitation is more intense (not shown), but this correspondence shows only consistency, not causality.
} 


\section{Precip \& $\mathbf{V}_{850}$}

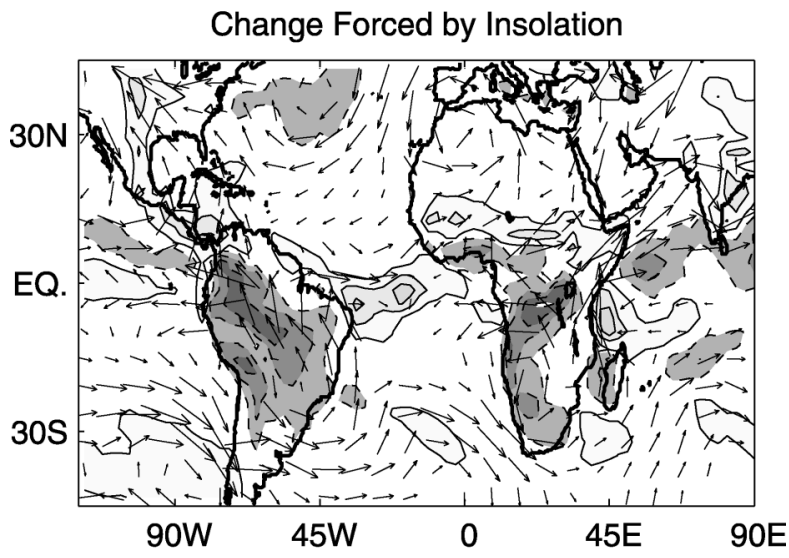

Change Forced by Africa+S.America Heating

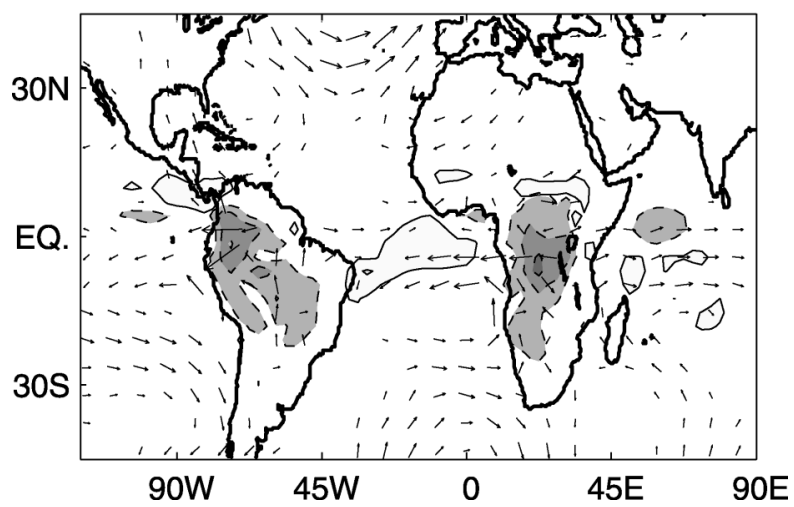

FIG. 9. (a) Jun-Mar precipitation and $850-\mathrm{mb}$ wind anomalies in the varying insolation experiment (precipitation c.i. $=4 \mathrm{~mm} \mathrm{day}^{-1}$, starting at \pm 2 negative values are dashed and shaded in dark gray, positive values are solid and shaded in lighter gray; only wind anomalies greater than $0.75 \mathrm{~m} \mathrm{~s}^{-1}$ are plotted). (b) Precipitation and 850$\mathrm{mb}$ wind difference between the perpetual Mar with Jun Africa and South America heating run and the perpetual Mar run [plotting convention as in (a)].

heating field over selected areas (Africa only, South America only, both Africa and South America, or the whole tropical belt except the Atlantic Ocean). In these regions we disregard the elevated heating field computed by the model at any time step, and we impose a constant heating that is taken from the output of the varying insolation simulation and corresponds to June insolation conditions over land. Any change in the intensity of precipitation in the Atlantic ITCZ between one of these "modified heating" simulations and a control perpetual March simulation should be interpreted as forced by June-March changes in convection in the selected area.

Figure $9 \mathrm{~b}$ shows precipitation and $850-\mathrm{mb}$ wind changes forced by the June-March elevated condensation heating difference over both South America and
Africa (perpetual March with June South America and Africa heating minus perpetual March). We first note that, as was seen in section 3 in reference to the ITCZ, forcing the atmosphere with a given elevated heating does not induce a consistent precipitation intensity at the location of the forcing (cf. Figs. 9a and 9b over South America and Africa). More importantly, we note that the elevated condensation heating in the African and South American convection centers does indeed force more intense rainfall in the Atlantic ITCZ, but the response in the central and western Atlantic is only a third of that caused by the full continental forcing (cf. Figs. 9a and 9b over the Atlantic). Additional experiments in which the elevated condensation heating is imposed over South Africa only or over South America only indicate that the two continental convection centers play comparable roles in producing the rainfall anomalies in the ITCZ, but the response to African heating is more widespread and somewhat stronger (Fig. 11). Moreover, the low-level wind in the Atlantic responds predominantly to the African forcing.

Finally, an experiment in which the elevated condensation heating is imposed over the entire tropical belt except the Atlantic Ocean, exhibits a response in the Atlantic ITCZ that is closer to what is seen in Fig. 9a in terms of spatial extent (it reaches the northeast coast of South America) and intensity (it reaches a peak value of $6 \mathrm{~mm} \mathrm{day}{ }^{-1}$ ), but is still too weak (not shown).

Figures $10 \mathrm{~b}$ and $10 \mathrm{~d}$ show the profiles of $\theta, \theta_{e}$, and $\theta_{\mathrm{es}}$ in the equatorial Atlantic. Both simulations were done under March SST and insolation conditions but one (Fig. 10b) has March elevated condensation heating conditions in South America and Africa and the other (Fig. 10d) has June elevated condensation heating imposed over South America and Africa. It is apparent that the June reduction in continental convection cools the upper troposphere over the Atlantic but not the lower half of the column. The overall effect is to enhance CAPE and induce the intensification of precipitation in the ITCZ, but such intensification does not match what seen in the varying insolation experiment (Figs. 10a,c). We attribute this mismatch to the vertical structure of the cooling, which implies a small increase of stability at about $700 \mathrm{mb}$.

A better match between, on the one hand, the response of Atlantic ITCZ rainfall to changes in continental elevated heating and, on the other hand, the response to changes in insolation over land (or, equivalently, to changes in both convection and surface temperature) can be achieved by adjusting the imposed heating over Africa and South America to mimic the inclusion of the corresponding changes in radiative heating alongside the changes in condensation heating (not shown). By so doing, we better match the changes in the heating vertical profile associated with changes in precipitation in the varying insolation simulation. We conclude that the intensity of the ITCZ responds to remote convection, as hypothesized, and that the magnitude of the response 
a. June Insolation

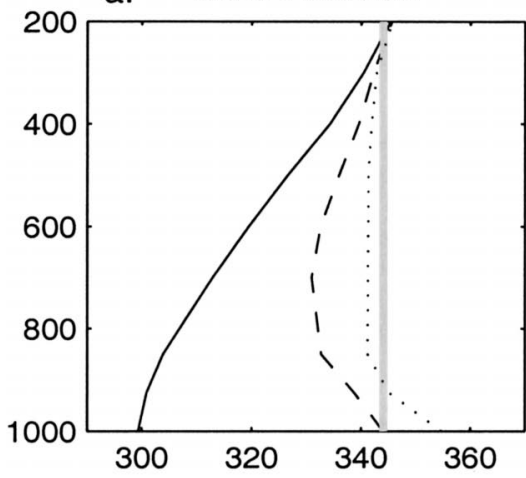

C. March Insolation

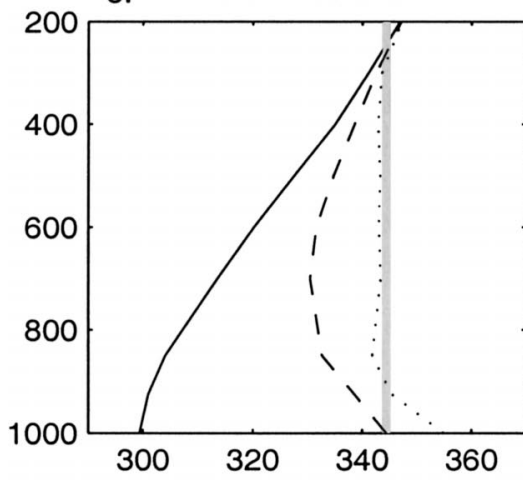

e. Difference a.-d.

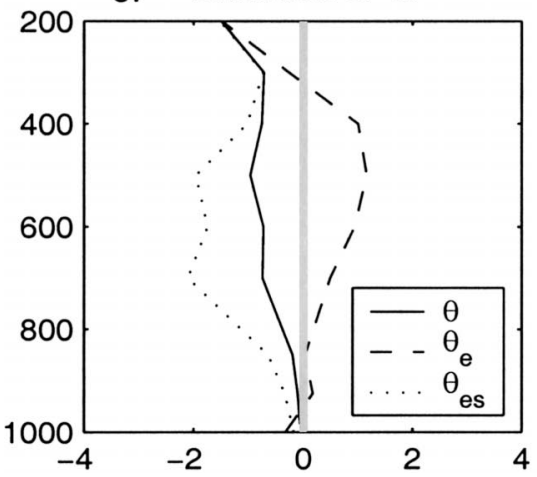

bJune Africa+S.America $Q$

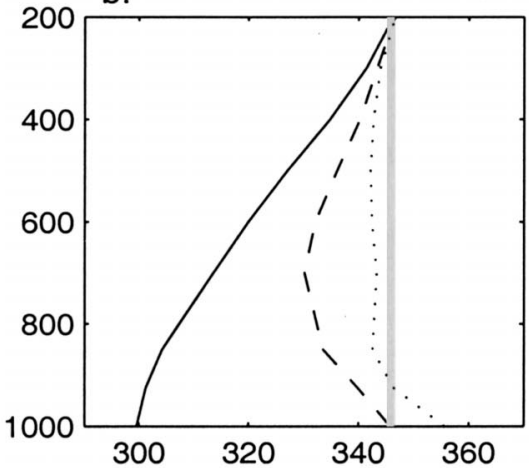

d. Perpetual March

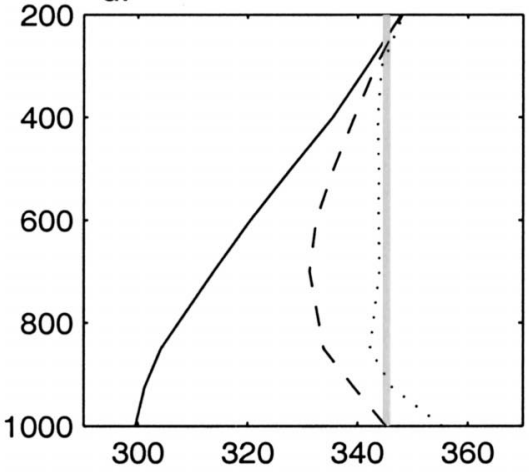

f. Difference b.-d.

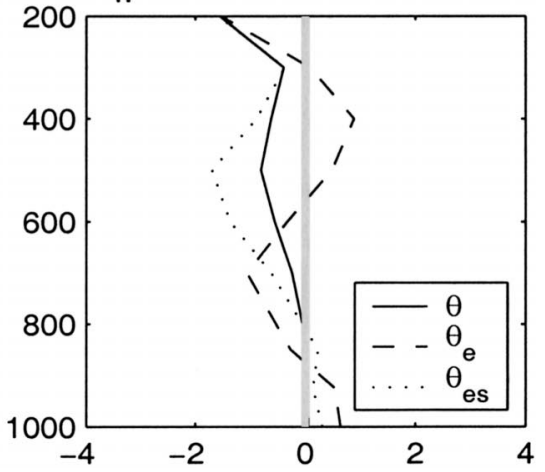

FIG. 10. Vertical profiles of potential temperature $(\theta$, solid), equivalent potential temperature $\left(\theta_{e}\right.$, dashed), and saturated equivalent potential temperature $\left(\theta_{\mathrm{es}}\right.$, dotted) over the location of the Mar maritime ITCZ $\left(7^{\circ} \mathrm{N}-0^{\circ}, 40^{\circ}-5^{\circ} \mathrm{W}\right)$ in the (left column) varying insolation experiment, (b) the perpetual Mar with Jun Africa and South America heating run, and (d) the perpetual Mar run.

is quite sensitive to the details of the profile of the imposed remote heating.

Another interesting feature of the response to continental heating is its spatial scale. Dry models (Gill 1980; Schneider 1987) would suggest a Tropics-wide response to a deep convective heating (small, widespread subsidence would compensate for upward mass flux in the region of the imposed positive isolated heating and vice versa). While our results support that the tropospheric temperature response is nearly homogeneous throughout the Tropics (not shown), experiments in which elevated condensation heating is imposed over one continent at a time (Fig. 11) indicate that the response in precipitation, vertical motion, and low-level wind is inhomogeneous. The reason for the inhomogeneity in the precipitation response can be explained in terms of stability threshold: if, for example, the profile is very stable, a small upper-level cooling will not create a precipitation anomaly. Thus, we expect a larger response where the basic state already has precipitation. To understand why 


\section{a. Prec.\& $\mathbf{V}_{850}$ due to South African Heating}

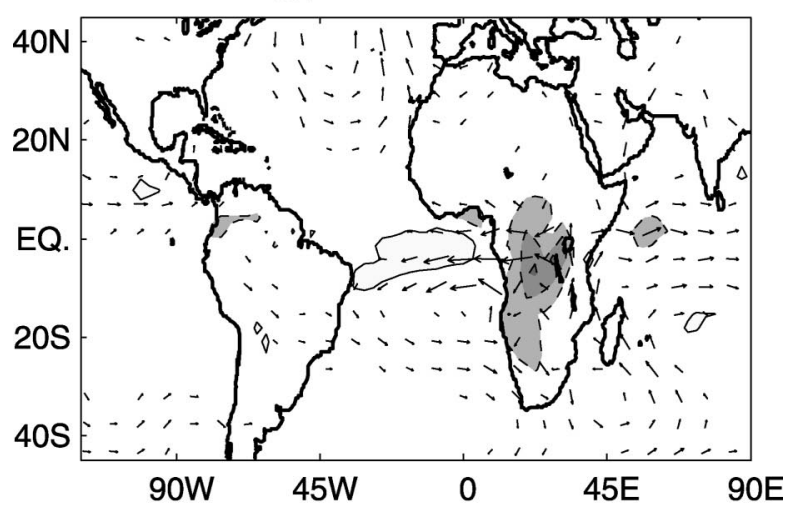

b. Prec.\& $\mathbf{V}_{850}$ due to South American Heating

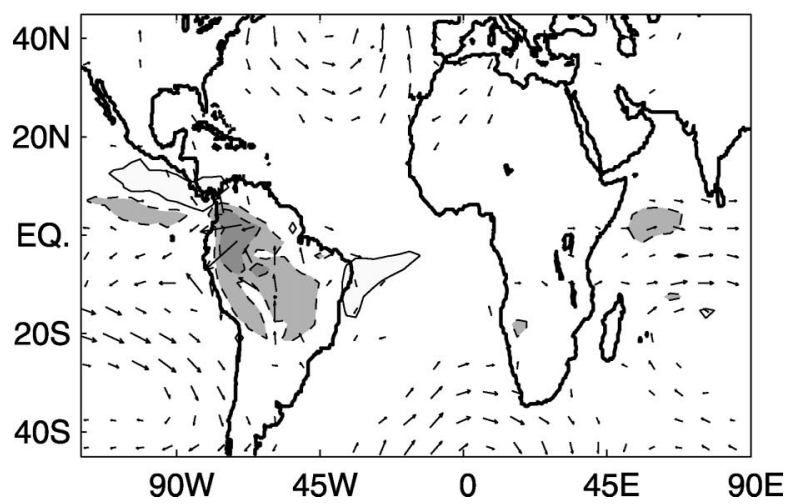

FIG. 11. (a) Precipitation and 850-mb wind difference between the perpetual Mar with Jun South Africa heating run and the perpetual Mar run (precipitation c.i. $=4 \mathrm{~mm} \mathrm{day}^{-1}$, starting at \pm 2 negative values are dashed and shaded in dark gray, positive values are solid and shaded in lighter gray; only wind anomalies greater than 0.75 $\mathrm{m} \mathrm{s}^{-1}$ are plotted). (b) Same as in (a) but for South American heating.

the circulation is also inhomogeneous, one has to invoke the most basic balance in the Tropics: diabatic heating and adiabatic heating balance each other. The diabatic heating response depends on the basic state; therefore, the same must hold true for the vertical motion field and the associated divergent circulation. How the atmosphere achieves this adjustment in our experiments has not been established.

\section{Summary and discussion}

The purpose of this paper is to identify the mechanisms that determine the annual cycle of precipitation in an atmospheric general circulation model (AGCM) with prescribed SST. In particular, our aim is to identify how changes in local insolation affect precipitation over the tropical continents, how changes in SST (which in our model experiments can be prescribed independently from insolation) affect precipitation in the ITCZ, and how temperature and rainfall over the ocean affect precipitation over the continents and vice versa.
We remark that, in the experiments presented in this paper, the SST is prescribed, whereas in the real world it is determined by both the local insolation and the oceanic response to atmospheric forcings through inherently coupled processes. This is an important limitation and is partially addressed in a companion paper (BBS2). Nevertheless, this study offers some valuable insight on how our AGCM models-and, by inference, nature-produce the observed annual cycle of precipitation in the tropical Atlantic sector. The general conclusion that can be drawn from this study is that the observed annual cycle of precipitation over the Atlantic sector is the product both of local insolation and of interactions between the landmasses and the ocean. Next, we offer a summary description of the mechanisms by which continental and maritime precipitation responds to local and remote forcings.

\section{a. Local control of continental precipitation}

The response of continental precipitation in the Tropics to insolation can be explained in the context of the Neelin and Held (Neelin and Held 1987) simple theoretical model, which states that a positive net energy input in the atmospheric column $\left(F_{\text {net }}\right)$ is balanced by horizontal energy export in a thermally direct circulation, and thus is associated with convection. To zeroth order, the varying insolation experiment supports the conclusions of this simple model: the seasonal changes in precipitation mimic the seasonal changes in $F_{\text {net }}$ in most of the tropical landmasses, with the notable exception of the Sahara, where $F_{\text {net }}$ never becomes positive and convection cannot be sustained-even if the seasonal changes in $F_{\text {net }}$ are substantial. In the main continental convection centers summer rainfall is enhanced because summer insolation decreases atmospheric stability. In the monsoon regions, stability is unaffected by insolation, and the enhanced moisture flow in the monsoon is the key ingredient for rainfall.

The varying insolation experiment suggests the following implications for modeling the annual cycle of precipitation over the tropical continents in a coupled GCM. Outside of the equatorial belt and the Sahel, where the influence of remote SST is important, gross shortcomings in the simulation of precipitation are most likely attributable to the atmosphere-land component of the model and not to the effect of coupling. In particular, the land albedo, determined by soil type, soil moisture, and vegetative cover, can strongly affect $F_{\text {net }}$ and thus can have a large impact on precipitation.

\section{b. Local control of oceanic precipitation}

In the uncoupled simulations described in this study, the seasonal movement of the ITCZ is controlled by seasonal changes in SST: the ITCZ lies over the warmest waters. The response of precipitation to the SST field is determined by boundary layer processes, as first de- 
scribed by Lindzen and Nigam (1987). The atmospheric boundary layer hydrostatically adjusts to an increase in SST and produces a low-level thermal low. The resulting wind converges moisture into the low, sustaining convection. An experiment with prescribed elevated condensation heating in the ITCZ suggests that, although boundary layer processes are the fundamental reason why the ITCZ follows the warmest SST, the ITCZ is more than a passive participant, even in this uncoupled experiment. The elevated condensation heating in the ITCZ drives a substantial low-level flow and moisture convergence.

This result is similar to the results of Chiang et al. (2001), who found that at interannual-to-decadal time scales both the SST gradient and the heating anomalies associated with the displacement of the ITCZ force surface convergence and meridional wind in the equatorial Atlantic. Differences in the details of the response to elevated heating between our study and theirs might be explained by the difference in the forcings used. In the study of Chiang et al. (2001), the convective heating anomalies used to force the model are mostly confined to the equatorial belt, whereas in our study they extend to $15^{\circ} \mathrm{N}$. Another possible explanation is that the details of the simulated atmospheric response to elevated heating are dependent on the characteristics of the model, such as the treatment of the boundary layer processes and radiation.

The strong surface wind response to elevated heating suggests the possibility of strong feedbacks between the ITCZ and the SST in experiments in which the SST is interactive. One implication is that we can expect the Atlantic ITCZ to have larger variability in POGA + MXL simulations (Pacific Ocean Global Atmosphere and Mixed Layer: experiments in which the observed time series of SST is prescribed in the tropical Pacific, and SST is calculated by a mixed layer model elsewhere) than in GOGA simulations (Global Ocean Global Atmosphere: experiments in which the observed time series of SST is prescribed everywhere). A preliminary analysis of runs provided by P. Chang and R. Saravanan supports this conclusion.

Finally, we want to suggest some caution regarding the interpretation of the local response to imposed heating. An elevated heating source changes the stability of the atmosphere, so that the model precipitation (and the circulation that sustains it) and the imposed heating are not consistent with each other.

\section{c. Remote control of continental precipitation}

The response of continental precipitation to SST changes is concentrated in the coastal regions adjacent to the ITCZ and in the African Sahel. The seasonal changes in precipitation in coastal regions appear to be an indirect response to SST changes and can be forced by specifying the changes in elevated condensation heating associated with the seasonal movement of the ITCZ.
In contrast, precipitation in the Sahel responds directly to changes of SST.

In our experiments, we find that the influence of SST on Sahel precipitation at the annual time scale can be explained in terms of the influence of SST on the location of the $\theta_{e}$ maximum, determined by the SST field in the whole Atlantic basin (for West Africa) and the whole tropical ocean (for East Africa). Specifically, the $\theta_{e}$ profile in West Africa seems to evolve into its September value by means of an interactive adjustment involving first the response of the boundary layer atmosphere in the Atlantic basin to SST changes directly underneath, then the advection of temperature anomalies from the northern Atlantic over the Sahara, and finally the advection of moisture from the Gulf of Guinea and equatorial Africa into the Sahel. The mechanisms by which the Indo-Pacific basin affects the annual cycle of precipitation in central Africa are less clear.

In summary, our results for the annual cycle suggest that the covariability between Sahel rainfall and the Atlantic ITCZ is due to the presence of a common forcing, namely, SST, and not to the fact that the circulation associated with the ITCZ forces anomalies in the Sahel. In contrast, precipitation in the Nordeste, the Guiana Highlands, and the Guinea region is affected by the elevated heating in the ITCZ, and only indirectly by SST.

\section{d. Remote control of oceanic precipitation}

In the uncoupled experiments presented here, the main response of the oceanic precipitation to remote forcings coming from the continents is a change of intensity. The intensity of the maritime ITCZ responds to changes in continental precipitation: less precipitation over the continents induces a cooling of the upper troposphere and a more unstable environment [or equivalently, more convective available potential energy, (CAPE)] over the Atlantic. It stands to reason, then, that a larger upper-level cooling will force a larger response in the Atlantic ITCZ and, in fact, the ITCZ response is quite linear. For example, the responses to convective heating forcings imposed over Africa only and over South America only add up to the response obtained by imposing the forcings over both Africa and South America together. What controls the limited spatial extent of the precipitation response as not been explored in detail.

Sensitivity experiments in which the heating was adjusted to reproduce the vertical profile of the full convective forcing (i.e., the sum of the condensation and radiative heating associated with convection) suggest that the ITCZ response to remote elevated heating is quite sensitive to the details of the heating profile, consistent with Schumacher et al. (2003).

That the oceanic convection responds to the intensity of precipitation in the tropical continents via its response to changes in upper-troposphere temperature explains why land-induced precipitation anomalies over the 
ocean are collocated with the basic-state ITCZ (BBS1). An upper-level decrease in temperature is felt as an increase of CAPE in regions in which the atmosphere is conditionally unstable to begin with, but is not enough to make a stable column unstable. Conversely, if the SLP changes induced by land surface temperature were the main driver for ocean precipitation changes, we would expect that the basic-state SST would not matter as much, because surface wind responds linearly to SLP changes (Lindzen and Nigam 1987).

The response of the Atlantic ITCZ to continental precipitation suggests the idea that the CCM3 biases in precipitation over the tropical Atlantic sector-wherein precipitation over land is overestimated and precipitation over the equatorial ocean is underestimated (BBS1) - might be related problems. This indicates that changing the land surface properties in a way as to reduce land precipitation might be a viable way to address both problems.

Acknowledgments. The authors wish to thank Mike Wallace, Dennis Hartmann, Alessandra Giannini, and especially John Chiang for their insightful suggestions and editorial comments. This publication is supported by a grant to the Joint Institute for the Study of the Atmosphere and Ocean (JISAO) under NOAA Cooperative Agreement NA17RJ1232.

\section{REFERENCES}

Biasutti, M., 2000: Decadal variability in the tropical Atlantic as simulated by the Climate System Model and the CCM3 coupled to a slab ocean model. M.S. thesis, Dept. of Atmospheric Sciences, University of Washington, $43 \mathrm{pp}$.

_ D. S. Battisti, and E. S. Sarachik, 2003: The annual cycle over the tropical Atlantic, South America, and Africa. J. Climate, 16, 2491-2508.

,-- and -2005 : Terrestrial influence on the annual cycle of the Atlantic ITCZ in an AGCM coupled to a slab ocean. $J$. Climate, in press.

Chang, P., J. Li, and H. Li, 1997: A decadal climate variation in the tropical Atlantic Ocean from thermodynamic air-sea interactions. Nature, 385, 516-518.

Chiang, J. C. H., and A. H. Sobel, 2002: Tropical tropospheric temperature variations caused by ENSO and their influence on the remote tropical climate. J. Climate, 15, 2616-2631.

_ S. E. Zebiak, and M. A. Cane, 2001: Relative roles of elevated heating and surface temperature gradients in driving anomalous surface winds over tropical oceans. J. Atmos. Sci., 58, 13711394.

Chou, C., and J. D. Neelin, 2003: Mechanisms limiting the northward extent of the northern summer convection zones. J. Climate, 16, 406-425.

DeWitt, D. G., E. K. Schneider, and A. D. Vernekar, 1996: Factors maintaining the zonally asymmetric precipitation distribution and low-level flow in the Tropics of an atmospheric general circulation model: Diagnostic studies. J. Atmos. Sci., 53, 2247 2263.

Folland, C. K., T. N. Palmer, and D. Parker, 1986: Sahel rainfall and worldwide sea temperature. Nature, 320, 602-687.

Giannini, A., R. Saravanan, and P. Chang, 2003: Oceanic forcing of Sahel rainfall on interannual to interdecadal time scale. Science, 302, 1027-1030.

Gill, A. E., 1980: Some simple solutions for heat-induced tropical circulation. Quart. J. Roy. Meteor. Soc., 106, 447-462.

Hack, J., J. Kiehl, and J. Hurrell, 1998: The hydrologic and thermodynamic characteristics of the NCAR CCM3. J. Climate, 11, $1207-1236$

Hastenrath, S., 1984: Interannual variability and the annual cycle: Mechanisms of circulation and climate in the tropical Atlantic sector. Mon.Wea. Rev., 112, 1097-1107.

and L. Greischar, 1993: Further work on the prediction of Northeast Brazil rainfall anomalies. J. Climate, 6, 743-758.

Lindzen, R. S., and S. Nigam, 1987: On the role of sea surface temperature gradients in forcing low-level winds and convergence in the Tropics. J. Atmos. Sci., 44, 2418-2436.

McGauley, M., C. Zhang, and N. Bond, 2004: Large-scale characteristics of the atmospheric boundary layer in the eastern Pacific cold tongue-ITCZ region. J. Climate, 17, 3907-3920.

Mitchell, T. P., and J. M. Wallace, 1992: The annual cycle in equatorial convection and sea surface temperature. J. Climate, 5, 11401156.

Neelin, J. D., and I. M. Held, 1987: Modeling tropical convergence based on the moist static energy budget. Mon. Wea. Rev., 115, $3-12$.

Schneider, E. K., 1987: A simplified model of the modified Hadley circulation. J. Atmos. Sci., 44, 3311-3328.

-, L. Bengtsson, and Z.-Z. Hu, 2003: Forcing the Northern Hemisphere climate trends. J. Atmos. Sci., 60, 1504-1521.

Schumacher, C., R. A. Houze Jr., and I. Kraucunas, 2003: The tropical dynamical response to latent heating estimates derived from TRMM precipitation radar. J. Atmos. Sci., 61, 1341-1358.

Sobel, A. H., and C. Bretherton, 2000: Modeling tropical precipitation in a single column. J. Climate, 13, 4378-4392.

- $-\ldots$, H. Gildor, and M. E. Peters, 2004: Convection, cloudradiative feedbacks and thermodynamic ocean coupling in simple models of the Walker circulation. Earth Climate: The OceanAtmosphere Interaction, Geophys. Monogr., No. 147, Amer. Geophys. Union, 1-19.

Wu, Z., D. S. Battisti, and E. S. Sarachik, 2000a: Rayleigh friction, Newtonian cooling, and the linear response to steady tropical heating. J. Atmos. Sci., 57, 1937-1957.

_ - E. S. Sarachik, and D. S. Battisti, 2000b: Vertical structure of convective heating and the three-dimensional structure of the forced circulation on an equatorial beta plane. J. Atmos. Sci., $\mathbf{5 7}, 2169-2187$ 